\title{
Concurrent activation of high- and low-level production processes in written composition
}

\author{
THIERRY OLIVE \\ University of Paris 8 and CNRS, Saint-Denis, France \\ and \\ RONALD T. KELLOGG \\ University of Missouri, Rolla, Missouri
}

\begin{abstract}
Writing a text requires the coordination of multiple high-level composition processes in working memory, including planning, language generation, and reviewing, in addition to low-level motor transcription. Here, interference in reaction time (RT) for detecting auditory probes was used to measure the attentional demands of (1) copying in longhand a prepared text (transcription), (2) composing a text and pausing handwriting for longer than $250 \mathrm{msec}$ (composition), and (3) composing and currently handwriting (transcription + composition). Greater interference in the transcription + composition condition than in the transcription condition implies that high-level processes are activated concurrently with motor execution, resulting in higher attentional demands. This difference was observed for adults who wrote in standard cursive, but not for children and not for adults who used an unpracticed uppercase script. Greater interference in the composition condition than in the transcription condition implies that high-level processes demand more attention than do motor processes. This difference was observed only when adults wrote with a practiced script. With motor execution being relatively automatic, adults were able to attend fully to the high-level processes required in mature, effective composition. One reason that children fail to engage in such high-level processes is that motor processes deplete available attention.
\end{abstract}

Writing processes place demands on working memory resources, and coordination of access to these limited resources appears to be a central problem in composition (Fayol, 1999; Flower \& Hayes, 1980; Kellogg, 1996; Ransdell \& Levy, 1996; Torrance \& Jeffery, 1999). The demands of high-level composition processes, including planning, language generation, and reviewing, must be juggled with those of low-level motor transcription. Planning the content of discourse involves memory retrieval, problem solving, and decision making. The conceptual content must then be translated into sentences via linguistic processes, such as grammatical encoding (Bock \& Levelt, 1994). Motor transcription typically closely follows sentence generation (Berninger \& Swanson, 1994). Reviewing text production involves reading text and detecting errors or problems either in the text or in the plans for

The work was supported by a NATO Collaborative Research Grant (LST.CLG 974939) and by a Doctoral Fellowship of the French Ministère de l'Enseignement Supérieur et de la Recherche awarded to the first author. We thank Annie Piolat for her help in designing the experiments and for her comments on a first version of this manuscript and two anonymous reviewers for their constructive suggestions. Correspondence concerning this article should be sent to T. Olive, Université de Paris 8 and CNRS (ESA 7021), Lab. "Cognition \& Activités Finalisées," 2, rue de la Liberté, F-93526Saint-Denis, Cedex, France (e-mail: thierry. olive@univ-paris8.fr).

- Accepted by previous editorial team text (Hayes, 1996). The high-level processes of planning, sentence generation, and reviewing demand substantial resources in adults (Kellogg, 1988, 1994). Even low-level motor transcription is demanding in children for whom handwriting is not yet automatic (McCutchen, 1996). Although working memory is not the only resource constraint on writing and not the only developmental difference of interest, it is one worthy of further investigation.

One way to cope with the demands of the writing processes is to alternate among them. Another way might be to divide the resources of working memory between a high-level process and motor transcription. Sharing working memory among writing processes assumes that the processes compete for a common resource-namely, the executive or attentional component (Kellogg, 2001). If motor execution demands little attention, a high-level process, such as planning, might concurrently share the executive component of working memory. Such concurrent activation might allow better coordination of high-level processes. If it were necessary to focus attention first on planning, second on generation, and third on motor execution, it would reduce the opportunity for rapid interactions between planning and generation. Although potentially advantageous, the concurrent activation of highand low-level processes should be limited to situations in which motor execution is relatively undemanding.

Brown, McDonald, Brown, and Carr (1988) found that as more stress was placed on speed, as opposed to legi- 
bility of handwriting, spelling errors and legibility decreased in the transcription of text. Interestingly, this decrease was reliably greater when a text was recalled from memory, which demanded planning, than when a text was simply read. Such an outcome is consistent with the view that planning competes with motor execution for attention. Competition between motor output and retrieval from memory is particularly acute in children even when speed is not emphasized, because handwriting is not yet automatized (Bourdin \& Fayol, 1994). Difficulties with motor transcription in children are known to correlate with poor writing skills (Graham, Berninger, Abbott, Abbott, \& Whitaker, 1997).

The high demands and difficulties of motor transcription in children not only preclude concurrent activation of other processes, they may explain, in part, why young writers fail to engage in high-level processes (McCutchen, 1996). For example, Bereiter and Scardamalia (1987) have shown that children retrieve an idea and generate and transcribe a sentence (knowledge-telling), rather than engaging in the reflective planning and reviewing processes characteristic of adult writers (knowledgetransforming). Relative to adults, children do not read what they have written, edit their texts, or struggle with sentence construction, local coherence, and global coherence (McCutchen, 1996). If this view is correct, transcription ought to be as demanding of attention, if not more so, as the high-level composition processes managed by children. For adults, composition processes should demand more capacity than does transcription.

It was hypothesized, then, that direct measurements of spare attentional resources during text production would reveal different profiles for children and adults. The measurements were made by having the writers rapidly detect auditory probes during transcription and composition. Focusing attention on the probe and scheduling a response engage executive functions of working memory (Jonides \& Smith, 1997). The degree of spare capacity available was measured in terms of reaction time (RT) interference. Baseline RT for detecting auditory probes was subtracted from the RT obtained in various writing conditions. The greater the interference in RT, the more attentional capacity or cognitive effort the writing processes required at the moment of the probe (Kahneman, 1973). It has been shown elsewhere that a secondary RT task involving auditory probes does not disrupt writing performance (Kellogg, 1994; Olive, Kellogg, \& Piolat, 2001; Piolat, Olive, Roussey, Thunin, \& Ziegler, 1999; Piolat, Roussey, Olive, \& Farioli, 1996).

Here, interference with RTs for detecting auditory probes was used to measure spare attentional capacity while (1) a prepared text was copied in longhand (transcription), (2) a text was composed and there was a pause in handwriting for longer than $250 \mathrm{msec}$ (composition), and (3) composing and handwriting were performed concurrently (transcription + composition). These three measurement conditions were assessed for third grade children, for adults who used standard cursive script, and for adults who used an unpracticed uppercase script. If the writers concurrently activate high-level composition processes during motor transcription, RT interference should be higher in the transcription + composition condition than in the transcription condition alone. If highlevel processes are engaged during pauses, RT interference should be greater in the composition condition than in the transcription condition. Both of these differences were expected for adults writing in standard script, for whom motor execution should be automatic.

If children omit much high-level processing to cope with the demands of motor execution, the transcription condition ought to yield just as much RT interference as the transcription + composition condition. Furthermore, children's RT interference ought to be greater overall than that observed in adults, because execution leaves little spare attentional capacity for probe detection. The transcription of prepared copy ought to reveal more RT interference with adults who are writing in uppercase script, as compared with adults who are using their usual handwriting. Furthermore, the uppercase script ought to preclude any difference between the transcription and the transcription + composition conditions. As with children writing in standard script, the adults writing in an unpracticed script should have difficulty activating a high-level process concurrently with motor execution.

An additional prediction concerned writing fluency, as measured by words produced per minute (wpm). This prediction follows from the idea that children are simply retrieving an idea, generating a sentence, and then transcribing the sentence (Bereiter \& Scardamalia, 1987). Although these processes are highly demanding for children, the demands of the composition task are more similar to those of the transcription of prepared text for them than they are for adults. Only the adults engage in extensive planning, generating, reading, and error detection during composition. The heavy demands of transcription and the limited high-level processes engaged by children should also be apparent in a slow rate of production, as compared with adults. Although adults should be faster overall than children, it was expected that the production rate of only the adults should decrease markedly for composing, relative to copying. For children, there is little difference between the two tasks. Only in adults are the high-level processes of composition more demanding than motor transcription.

Individual differences in working memory capacity were also examined, using a reading span test. This was done to validate that the children tested had less working memory capacity than adults but that different samples of adults did not vary. Whether adults with high capacity were able to activate processes concurrently more readily than those with low capacity was also assessed.

\section{METHOD}

\section{Participants}

Fifty-seven volunteers participated in this experiment. Seventeen participants were third graders (mean age, 9 years 4 months) from 
a French public primary school, and 40 were undergraduate students (mean age, 25 years) of the University of Provence. Half of the undergraduate students composed and copied their text by using their usual handwriting (standard script group). The other half composed and copied their text by using cursive uppercase script (uppercase script group).

\section{Tasks}

To isolate execution and high-level components, the participants performed two primary tasks. Using a digitizing tablet and writing with an electronic pen with ink, they first composed a text and then copied it. This allowed us to categorize the writers' activity according to whether they were pausing or transcribing their text at the moment the probe occurred. More precisely, when the electronic pen was on the tablet or up less than $250 \mathrm{msec}$, RTs were categorized as transcription. Under this threshold, pauses were related only to transcription operations, such as, for example, a dot on the "i." Above this threshold, pauses were classified as time devoted to high-level processes_-planning, translating, or reviewing.

\section{Apparatus and Material}

The participants wrote on a Wacom digitizing tablet connected to an Apple LC computer with an electronic pen with ink. Software designed for the experiment and programmed in Hypertalk language controlled the secondary RT task and associated each RT with the writer's activity (i.e., pauses or transcription in the composition task and transcription in the copy task).

A French adaptation of Daneman and Carpenter's (1980) Reading Span Test was also administrated to the participants to assess their cognitive capacity (Desmette, Hupet, Schelstraete, \& Van Der Linden, 1995). Half of the participants were given the Reading Span Test at the beginning of the experimental session, and the others were given the test at the end.

\section{Procedure}

The experimental procedure involved the following steps. First, general instructions concerning the unfolding of the experiment were provided to the participants. Then, in order to compute their mean baseline RTs, all the participants executed only an RT task. Thirty auditory probes were randomly distributed in an interval with a mean of $10 \mathrm{sec}$ and a range of $5-15 \mathrm{sec}$. The participants were asked to react as rapidly as possible whenever they detected a probe by pressing on the space bar of a keyboard with their nondominant hand. The mean baseline RT of each participant was calculated from the last 25 RTs (the five first trials were treated as warm-up signals). Finally, the participants in the uppercase condition copied a cursive uppercase alphabet twice before beginning the text composition task.

In the second step of the experiment, the secondary RT task was introduced. The participants were informed that during the composition, they would occasionally hear auditory probes. The participants were asked to react as rapidly as possible to the probes. During the composition task, probes were distributed randomly in an interval with a mean of $30 \mathrm{sec}$ and a range of $15-45 \mathrm{sec}$. The participants composed a persuasive text. The instructions given to the children were the following:

For their birthday, children often enjoy organizing a party at their home. But sometimes, parents disagree with their children and refuse to invite many children to come into their home for the party. Can you write why children want to invite their friends for their birthday party? And can you also write why some parents do not want to organize the birthday party at home? You should try to answer these questions in composing a text.

The instructions provided to the two groups of adult participants were the following:

The universities are beginning to need more funding to renew their buildings and to buy new computers and educational materials. What do you think about an increase of the university tuition to cover these expenses? Can you write pro and con arguments regarding this increase in tuition?

The participants were informed that they could modify their text by adding, deleting, or rearranging words or sentences. They were told to take as much time as they needed to write their text. They were reminded to concentrate fully on their text but to respond as rapidly as possible to the auditory signals. When they finished composing, the participants had to press a special key on the keyboard to stop the secondary RT task.

Next, the participants copied their text on a digitizing tablet while again performing the secondary RT task. To improve accessibility of the written text, the participants read it twice before copying it. The text they had to copy was right in front of them. The participants were informed that they would continue to hear signals occasionally during the copy task and that they had to detect them as rapidly as possible. The experimenter asked the participants to copy their text as it was in the original composition, and they were told that they could not correct it. The children and adults in the standard condition were asked to copy the text with their usual handwriting. The adults in the uppercase condition were asked to copy their text by using a cursive uppercase script. The participants had no time limit to complete the copying task.

\section{RESULTS}

Three RT interference scores were calculated for each participant in the transcription, composition, and transcription + composition conditions. Each reflected the difference between the mean baseline RT for the participant and the mean RT interference obtained in the three different situations. The scores measured the attention devoted to writing and are plotted in Figure 1. A preliminary analysis revealed reliably slower baselines for children $[M=646 \mathrm{msec}, S E=17]$ and adults [standard group, $M=550 \mathrm{msec}, S E=12$; uppercase group, $M=$ $559 \mathrm{msec}, S E=10 ; F(2,54)=19.55, M S_{\mathrm{e}}=3,249.98, p<$ $.001]$.

To examine whether RT interference differed across the transcription, composition, and transcription + composition measurement conditions in the three groups tested, an analysis of variance (ANOVA) was conducted. As was predicted, the measurement $\times$ group interaction was significant $\left[F(4,108)=10.403, M S_{\mathrm{e}}=5,561.83, p<\right.$ $.001] .{ }^{1}$

Planned contrasts revealed greater RT interference for copying a prepared text for children $(M=398 \mathrm{msec}, S E=$ $45)$, relative to the adults in the standard group $[M=$ $134 \mathrm{msec}, S E=17 ; F(1,35)=34.773, M S_{\mathrm{e}}=18,426.08$, $p<.001]$ and in the uppercase group $[M=217 \mathrm{msec}$, $\left.S E=17 ; F(1,35)=16.617, M S_{\mathrm{e}}=18,028.17, p<.001\right]$. As was expected, RT interference was significantly shorter for adults in the standard group than for those in the uppercase group $\left[F(1,38)=12.946, M S_{\mathrm{e}}=5,385.71\right.$, $p<.001]$. Clearly, then, motor transcription by itself was more effortful for children than for adults writing in standard script. But when adults wrote in the unpracticed uppercase script, they also devoted more attention to transcription than they did when they used standard script.

The composition versus transcription contrasts indicate the relative demands of high- versus low-level pro- 


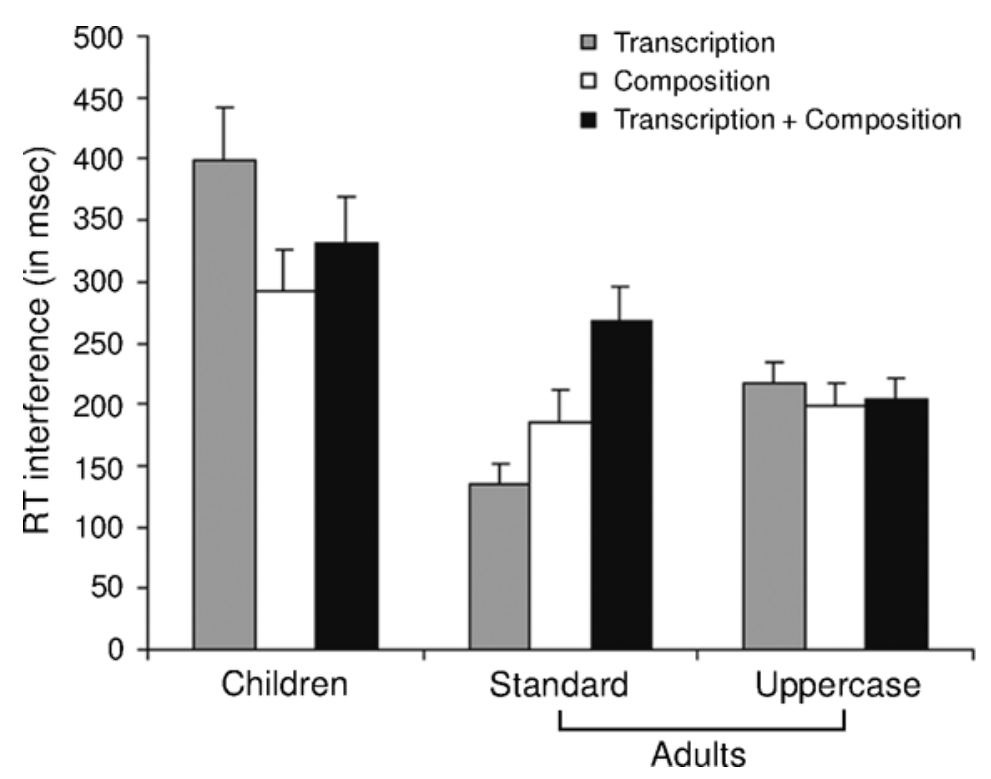

Figure 1. Mean secondary reaction time (RT) interference (in milliseconds) and standard errors for children, adults using standard script, and adults using uppercase script.

cesses. For adults using the uppercase script, the transcription condition was not reliably different from the composition condition. By contrast, adults using the standard script took significantly longer time to respond to the probes in the composition condition than when transcribing a prepared text $\left[F(1,19)=6.54, M S_{\mathrm{e}}=\right.$ $3,988.2, p<.05]$. The opposite pattern was observed in children, with reliably greater RT interference obtained during copy transcription than with the pauses of the composition condition $\left[F(1,16)=5.65, M S_{\mathrm{e}}=16,715.44\right.$, $p<.05]$. Thus, for children, the demands of motor transcription were actually greater than the demands imposed by pauses in writing. For adults, on the other hand, these pauses were used for high-level composition processes that demanded more attention than did transcription, at least when the standard practiced script was used.

Another contrast of interest revealed that the RT interference obtained during transcription was not different from that found in the transcription + composition condition for children. Similarly, for the adults writing in uppercase, this contrast was unreliable. Thus, transcription + composition did not demand any more attention than did transcription alone, suggesting that high-level composition processes were not concurrently activated with motor transcription. In contrast, for adults writing with standard script, the transcription condition showed reliably less RT interference than did the transcription + composition condition $\left[F(1,19)=39.92, M S_{\mathrm{e}}=4,487.38\right.$, $p<.001]$. Thus, concurrent activation of composition processes and transcription was observed only for adults writing in standard script. In fact, the demands were so substantial in the transcription + composition condition that the adults writing in standard script showed as much RT interference as did children. ${ }^{2}$

\section{Writing Fluency}

Writing fluency, expressed in wpm, was calculated by dividing the total task time (copying or composing) by the total number of words written during each task. The ANOVA revealed a significant main effect of group $\left[F(2,54)=56.96, M S_{\mathrm{e}}=29.94, p<.001\right]$. The fluency of adults writing with standard script $(M=17.8 \mathrm{wpm}, S E=$ 1.5) was reliably higher $\left[F(1,35)=47.41, M S_{\mathrm{e}}=44.41\right.$, $p<.001]$ than children's fluency $(M=7 \mathrm{wpm}, S E=0.4)$ and adults' fluency with uppercase script $[M=5.7 \mathrm{wpm}$, $\left.S E=0.4 ; F(1,38)=73.09, M S_{\mathrm{e}}=39.45, p<.001\right]$. The latter two groups did not reliably differ.

The main effect of task was also reliable $[F(1,54)=$ 98.37, $\left.M S_{\mathrm{e}}=4.38, p<.001\right]$. Across groups, the participants were less fluent in the composition task $(M=$ $8.3 \mathrm{wpm}, S E=0.8)$ than in the copy task $(M=12.3 \mathrm{wpm}$, $S E=1.1)$. This reflects the additional time needed to plan and generate sentences, plus reviewing, as com-

Table 1

Number of Words Written per Minute in the Children, Adults with Standard Script, and Adults With Uppercase Script Conditions in a Copy and a Composition

\begin{tabular}{lrrrrr}
\hline & \multicolumn{4}{c}{ Task } \\
\cline { 2 - 4 } \multicolumn{1}{c}{ Group } & \multicolumn{2}{c}{ Copy } & & \multicolumn{2}{c}{ Composition } \\
\cline { 2 - 6 } \cline { 3 - 6 } & \multicolumn{1}{c}{ No. } & $S E$ & & No. \\
\hline Children & 8.0 & 0.5 & 6.1 & 0.5 \\
Adults, standard & 21.0 & 1.7 & 14.5 & 1.2 \\
Adults, uppercase & 7.3 & 0.4 & 4.1 & 0.2 \\
\hline
\end{tabular}


pared with motor transcription alone. However, this difference depended on the writer's age and the kind of script used. As was expected, the group $\times$ task interaction was significant $\left[F(2,54)=12.21, M S_{\mathrm{e}}=4.38, p<\right.$ .001 ; see Table 1]. Adults in the standard condition were reliably less fluent in the composition task $(-6.5 \mathrm{wpm})$ than in the copy task $\left[F(1,19)=41.42, M S_{\mathrm{e}}=10.31, p<\right.$ $.001]$. For children, the reduction in fluency in the composition task $(-1.9 \mathrm{wpm})$ was small but reliable $[F(1,16)=$ $\left.553.79, M S_{\mathrm{e}}=0.55, p<.001\right]$. The reduction in fluency in the composition task for adults using the uppercase script $(-3.2 \mathrm{wpm})$ was also reliable $[F(1,19)=63.41$, $\left.M S_{\mathrm{e}}=1.67, p<.001\right]$, but it was only half as large as the reduction obtained with standard cursive. As was the case with children, adults composing with an unpracticed script were able to come reasonably close to the production rate obtained with transcription. When the demands of transcription were heavy, adults began to neglect highlevel processes and to focus on motor execution.

\section{Textual Analyses}

To explore the issue further, analyses of texts produced by the two groups of adults (standard and uppercase script) were also conducted. No reliable differences were observed on syntactical measures (clause and sentence length, and spelling and grammatical errors). The quality of the texts were judged in terms of informational content and language usage (interrater reliabilities: Pearson's $r=.56$ for informational content, and $r=.53$ for language usage, $p<.001)$ and then combined into an overall measure of quality. The uppercase group showed lower mean overall quality scores than did the standard group $[F(1,38)=11.91, p<.01]$. This result corroborates the suggestion that increasing the allocation of attention to motor transcription in adults detracts from high-level processes, reducing the quality of the texts. ${ }^{3}$

\section{Reading Span Scores}

It was assumed that the children had less working memory capacity to allocate to writing than did the adults, and this was borne out by the reading span analysis. The main effect of writing condition was reliable $[F(2,54)=$ $\left.18.19, M S_{\mathrm{e}}=0.36, p<.001\right]$. Planned comparisons showed that the children's reading span score $(M=2.12, S E=$ 0.1 ) was reliably lower than that of the adults in the standard group $\left[F(1,35)=32.95, M S_{\mathrm{e}}=0.36, p<.001\right]$ and in the uppercase group $\left[F(1,35)=30.34, M S_{\mathrm{e}}=0.26, p<\right.$ $.001]$. Reading span scores of the two groups of adults were not reliably different (standard, $M=3.25, S E=$ 0.16 ; uppercase, $M=3.05, S E=0.14$ ).

\section{DISCUSSION}

Interference in RT to secondary probes was greater when measured in the transcription + composition condition relative to the transcription condition only for adults writing in a familiar standard script. For them, high-level writing processes (e.g., planning, language generation, reading, and editing) can be activated concurrently with motor transcription. In children, such concurrent activation was not observed, because the demands of motor transcription alone consumed too much attention. Put simply, only the adult writers were able to think and write at the same time. Alternating attention between high-level and low-level processes would be the only way children could compose the text. Consistent with this interpretation, when adults wrote in capital letters, an unpracticed script, they also failed to show concurrent activation of high- and low-level processes.

Converging evidence supports the conclusion that motor execution was most demanding in the children. Comparisons of the transcription of prepared copy showed more RT interference for children than for adults writing in standard script. It was also more attention demanding for adults writing in the unpracticed script, rather than in the practiced standard script.

Moreover, only for children were the RT interference measurements reliably higher in the transcription condition than in the composition condition, taken during pauses. This result reinforces the conclusion that motor transcription is exceptionally high for children, even more so than their skeletal high-level composition (Bereiter \& Scardamalia, 1987; McCutchen, 1996). For adults writing in standard cursive script, pauses during composition resulted in higher RT interference than was observed in the transcription condition, because they fully engaged high-level processes. In contrast to children, the planning, language generation, reading, and editing processes in adults demanded substantial attention, more so than did transcription. However, it proved possible to equate the two sources of demand by forcing the adults to devote more attention than normal to motor transcription when writing in uppercase letters.

It appears that adults can concurrently activate highand low-level processes in working memory when motor transcription is relatively automatic. This conclusion assumes that the temporal resolution of the method used here is adequate. If adults shifted from, say, language generation to motor transcription and then back to planning within $250 \mathrm{msec}$, it would only appear that the activations were concurrent and the resources divided. Although this could have occurred on occasion, it is not a compelling explanation of the results, for two reasons.

First, the 250-msec interval employed was too short for most epochs of planning, sentence generation, reading, and editing. For example, Levy and Ransdell (1995) have provided evidence that the intervals devoted to these high-level composition processes are on the order of several seconds. Other studies also have suggested that they are unlikely to begin and end within $250 \mathrm{msec}$ (Passerault, 1991; Schilperoord, 2001). Second, speech production in adults involves concurrent activation of sentence generation processes and the highly automatized motor output (Bock \& Levelt, 1994). Grammatically and then phonologically encoding the next phrase of a spoken sentence takes place as the motor system ex- 
ecutes the most recently formulated phrase. A similar procedure is plausible in written output when sufficient working memory resources can be allocated to handle both the high- and the low-level processes.

The findings reported here are consistent with past research suggesting that motor transcription demands a substantial degree of available working memory resources in children, leaving little available for high-level processes (Bourdin \& Fayol, 1994; Graham et al., 1997). Furthermore, the findings are consistent with McCutchen's (1996) suggestion that working memory limitations underlie children's failure to engage in high-level processes during text production. For example, the knowledge-telling strategy used by children simplifies the high-level processes involved in retrieving an idea and then generating a sentence to express it (Bereiter \& Scardamalia, 1987). Adults, in contrast, engage in many cycles of reflective planning, reading, and editing along with generation. The task itself is markedly different in children and adults - in part, at least, because adults have the working memory resources available for the more complex strategy of knowledge-transforming. Relative to adults, children do not read what they have written, edit their texts, or struggle with sentence construction, local coherence, and global coherence (McCutchen, 1996). Lack of capacity for high-level processes is one reason for these failures.

Finally, the fluency of adult writers slowed during composition, relative to the copy, when standard script was used. The division of attention between transcription and high-level processes forced a reduction in fluency. In contrast, children and adults writing in uppercase letters composed nearly as fast as they transcribed prepared text, albeit at a much slower rate overall in both cases. This finding supports the view that execution and high-level processes are competing for a common working memory resource (Bourdin \& Fayol, 1994; Kellogg, 2001). It further indicates that the rate of motor transcription in adults slows to accommodate the demands placed on high-level processes (Brown et al., 1988). The fluency rate dropped by $6.5 \mathrm{wpm}$ in adults writing in cursive in adjusting to high-level demands but only dropped by 1.9 wpm in children.

Fayol (1999) has argued that on-line coordination of writing processes can be achieved in two ways. The first is to automatize processes, but this may be limited to low-level processes, as opposed to high-level ones (McCutchen, 1988). The second is to adapt the rhythm of production when problems arise in integrating the demands of effortful processes. For example, Chanquoy, Foulin, and Fayol (1990) asked 8-year-old children and adult writers to complete stories under different constraints of complexity and predictability. They found that the adults, but not the children, increased the duration of their prewriting pauses and between-clause pauses and slowed slightly their within-clause writing rate when the events being written about in the story were predictable. The adults coordinated writing processes, in part, by slowing the rhythms of low-level motor processes to accommodate high-level processing demands. Similarly, Foulin (1995) asked children and adult participants to produce a sentence with two clauses. The duration of intraclause pauses in adults decreased in the second clause, and the rate of production accelerated at the end of the sentence, as the conceptual and linguistic demands waned. Similar variations were not observed in children, because motor transcription was demanding and inflexible in rate.

\section{REFERENCES}

Bereiter, C., \& Scardamalia, M. (1987). The psychology of written composition. Hillsdale, NJ: Erlbaum.

Berninger, V. W., \& Swanson, H. L. (1994). Modifying Hayes and Flower's model of skilled writing to explain beginning and developing writing. In J. S. Carlson (series ed.) \& E. C. Butterfield (vol. ed.), Advances in cognition and educational practice: Vol. 2. Children's writing: Toward a process theory of the development of skilled writing (pp. 57-81). Greenwich, CT: JAI Press.

Bock, K., \& LeVelt, W. (1994). Language production: Grammatical encoding. In M. A. Gernsbacher (Ed.), Handbook of psycholinguistics (pp. 945-984). New York: Academic Press.

Bourdin, B., \& FAYOL, M. (1994). Is written language production more difficult than oral language production? A working memory approach. International Journal of Psychology, 29, 591-620.

Brown, J. S., McDonald, J. L., Brown, T. L., \& Carr, T. H. (1988). Adapting to processing demands in discourse production: The case of handwriting. Journal of Experimental Psychology: Human Perception \& Performance, 14, 45-59.

Chanquoy, L., Foulin, J.-N., \& Fayol, M. (1990). Temporal management of short texts writing by children and adults. CPC/European Bulletin of Cognitive Psychology, 10, 513-538.

Daneman, M., \& Carpenter, P. A. (1980). Individual differences in working memory and reading. Journal of Verbal Learning \& Verbal Behavior, 19, 450-466.

Desmette, D., Hupet, M., Schelstraete, M. A., \& Van Der Linden, M. (1995). Adaptation en langue française du "reading span test" de Daneman et Carpenter [French adaptation of Daneman and Carpenter's "Reading Span" test]. L'Année Psychologique, 95, 459-482.

FAYOL, M. (1999). Writing: From on-line management problems to strategies. In M. Torrance \& G. Jeffery (Eds.), Cognitive demands of writing (pp. 13-23). Amsterdam: Amsterdam University Press.

Flower, L., \& HAYES, J. R. (1980). The dynamics of composing: Making plans and juggling constraints. In L. W. Gregg \& E. R. Steinberg (Eds.), Cognitive processes in writing (pp. 31-50). Hillsdale, NJ: Erlbaum.

Foulin, J.-N. (1995). Pauses et débits: Les indicateurs temporels de la production écrite [Pauses and writing rate: Temporal indexes of written composition]. L'Année Psychologique, 95, 483-504.

Graham, S., Berninger, V. W., Аввотt, R. D., Аввотt, S. P., \& WhITAKER, D. (1997). Role of mechanics in composing of elementary school students: A new methodological approach. Journal of Educational Psychology, 89, 170-182.

HAYES, J. R. (1996). A new framework for understanding cognition and affect in writing. In C. M. Levy \& S. E. Ransdell (Eds.), The science of writing: Theories, methods, individual differences and applications (pp. 1-27). Mahwah, NJ: Erlbaum.

Jonides, J., \& SMith, E. E. (1997). The architecture of working memory. In M. D. Rugg (Ed.), Cognitive neuroscience (pp. 243-276). Cambridge, MA: MIT Press.

Kahneman, D. (1973). Attention and effort. Englewood Cliffs, NJ: Prentice-Hall.

Kellogg, R. T. (1988). Attentional overload and writing performance: Effects of rough draft and outline strategies. Journal of Experimental Psychology: Learning, Memory, \& Cognition, 14, 355-365.

KellogG, R. T. (1994). The psychology of writing. New York: Oxford University Press. 
KellogG, R. T. (1996). A model of working memory in writing. In C. M. Levy \& S. E. Ransdell (Eds.), The science of writing: Theories, methods, individual differences and applications (pp. 57-71). Mahwah, NJ: Erlbaum.

KeLLOGG, R. T. (2001). Competition for working memory among writing processes. American Journal of Psychology, 114, 175-192.

Levy, C. M., \& Ransdell, S. E. (1995). Is writing as difficult as it seems? Memory \& Cognition, 23, 767-779.

McCutchen, D. (1988). Functional automaticity in children's writing: A problem of metacognitive control. Written Communication, 5, 306-324.

McCutchen, D. (1996). A capacity theory of writing: Working memory in composition. Educational Psychology Review, 8, 299-325.

Olive, T., Kellogg, R. T., \& Piolat, A. (2001). The triple task technique for studying the process of writing. In G. Rijlaarsdam (series ed.), T. Olive, \& C. M. Levy (vol. eds.), Studies in writing: Vol. 10. Contemporary tools and techniques (pp. 31-58). Dordrecht: Kluwer.

Passerault, J.-M. (1991). L'analyse en temps réel de l'activité de résumé: Une étude des temps de pause [On-line analysis of summarizing: A study of pausing times]. In M. Charolles \& A. Petitjean (Eds.), Le résumé de texte: Aspects linguistiques, sémiotiques, psycholinguistiques et automatiques (pp. 207-219). Paris: Klincksieck.

Piolat, A., Olive, T., Roussey, J.-Y., Thunin, O., \& Ziegler, J. C. (1999). SCRIPTKELL: A tool for measuring cognitive effort and time processing in writing and other complex cognitive activities. Behavior Research Methods, Instruments, \& Computers, 31, 113-121.

Piolat, A., Roussey, J.-Y., Olive, T., \& Farioli, F. (1996). Charge mentale et mobilisation des processus rédactionnels: Examen de la procédure de Kellogg [Mental load and activation of writing processes: Examination of Kellogg's procedure]. Psychologie Française, 41, 339-354.

RANSDELl, S. E., \& LeVy, C. M. (1996). Working memory constraints on writing quality and fluency. In C. M. Levy \& S. E. Ransdell (Eds.), The science of writing: Theories, methods, individual differences and applications (pp. 93-106). Mahwah, NJ: Erlbaum.

SCHILPEROORD, J. (2001). On the cognitive status of pauses in discourse production. In G. Rijlaarsdam (series ed.), T. Olive, \& C. M. Levy (vol. eds.), Studies in writing: Vol. 10. Contemporary tools and techniques (pp. 61-88). Dordrecht: Kluwer.
Torrance, M., \& JefFery, G. (EDS.) (1999). The cognitive demands of writing: Processing capacity and working memory effects in text production. Amsterdam: Amsterdam University Press.

\section{NOTES}

1. A significant main effect of group was also observed $[F(2,54)=$ $\left.11.68, M S_{\mathrm{e}}=29,933.78, p<.001\right]$. Comparisons using the Sheffé test revealed that RT interference for the children $(M=341 \mathrm{msec}, S E=23)$ was reliably $(p<.001)$ higher than that for the adults in the standard group $(M=196 \mathrm{msec}, S E=16)$ and in the uppercase group $(M=207 \mathrm{msec}$, $S E=10)$. The adult groups did not differ overall. Furthermore, the main effect of measurement was significant $\left[F(2,108)=4.61, M S_{\mathrm{e}}=5,561.83\right.$, $p<.05]$. Overall, the participants took less time to respond to the auditory probes while pausing during the composition $(M=225 \mathrm{msec}, S E=$ $17)$ than when transcribing $(M=268 \mathrm{msec}, S E=20)$ in the transcription + composition condition (Sheffé test, $p<.05$ ).

2. Effects of capacity differences in working memory were explored by dividing the participants into high reading span and low reading span groups, using a median split appropriate for the children and for the adults. Neither the RT interference data nor the fluency data revealed reliable differences between the high- and the low-span groups. Therefore, the data are reported for all the participants in the group averaged together.

3. The type of script also affected the number of revisions observed, as was shown in an analysis of covariance with the number of words written as the covariate $[F(1,37)=9.468, p<.05]$. The participants in the standard group revised their texts less frequently $(M=4.45, S E=0.86)$ than did the participants in the uppercase group $(M=7.15, S E=1.03)$. Presumably to achieve the low rate of spelling and grammatical errors obtained in the uppercase condition ( 0.013 spelling error by word and 0.012 grammatical errors by word), more revisions were required. Because the uppercase script was unpracticed, the writers slowed down production and reviewed their work more carefully than was found with the standard script.

(Manuscript received March 2, 2000; revision accepted for publication March 12, 2002.) 